\title{
Measuring the Acceleration of a Motorcycle
}

\author{
Petr Slepanek, Ing. \\ Institute of Forensic Engineering VUT in Brno, Czech Republic
}

Doi: 10.19044/esj.2018.v14n9p372 URL:http://dx.doi.org/10.19044/esj.2018.v14n9p372

\begin{abstract}
The paper describes problems of measuring the acceleration of a motorcycle. Measured motorcycle was traveling Honda CBR $1000 \mathrm{~F}$. Measurement was realized at a parking area with use of the two-axis accelerometer XL METR ${ }^{\mathrm{TM}}$ PRO GAMMA. The aim of the measurement was to determine the speed of acceleration at the normal (not fast, not slow) starting of the motorcycle at the first, second and third gears, followed by stabilization of the speed to the value required for urban traffic. Motorcycle acceleration values followed by the speed stabilization at $40 \mathrm{~km} / \mathrm{h}$ ranged from 1.8 to $2.1 \mathrm{~m} . \mathrm{s}^{-2}$. Motorcycle acceleration values followed by the speed stabilization at $50 \mathrm{~km} / \mathrm{h}$ ranged from 1.9 to $2.2 \mathrm{~m} . \mathrm{s}^{-2}$. Motorcycle acceleration values followed by the speed stabilization at $60 \mathrm{~km} / \mathrm{h}$ ranged from 2.1 to $2.2 \mathrm{~m} . \mathrm{s}^{-2}$. Achieved acceleration values were in the range from 1.8 to $2.2 \mathrm{~m} \cdot \mathrm{s}^{-2}$. Individual results of the measurement have been summarized in the tables and graphs. Technically acceptable parameters for motorcycle acceleration are not many, so the measured data in this article could be useful to experts for solving traffic accidents with the presence of a motorcycle.
\end{abstract}

Keywords: Acceleration, motorcycle, measurement, XL METR ${ }^{\mathrm{TM}}$ PRO GAMMA

\section{Introduction}

Accident analysis is a very complex process in which it is necessary to use current methods and procedures. Currently, simulation programs are used for the analysis of accidents, but an expert himself is still responsible for the accuracy of the results. The accuracy of the results depends on the suitably chosen solution method and the input parameters, which must be within technically acceptable limits. The problem is the lack of entry data of motorcycle acceleration, which are important for dealing with traffic accidents involving motorcycles.

Thanks to their low weight and high performance, today's motorcycles achieve high values of acceleration. The acceleration of various cubatures and motorcycle types range from 1.5 to $2.5 \mathrm{~m} . \mathrm{s}^{-2}$ with a slow start, from 2.5 to 3.5 
m.s ${ }^{-2}$ with a normal start and up to $6.5 \mathrm{~m} . \mathrm{s}^{-2}$ (Kasanicky \& Kohut, 2000) with a fast start - lower values usually correspond to lower cubatures. Acceleration values for motorcycles without a passenger vary from 3.0 to $3.5 \mathrm{~m} . \mathrm{s}^{-2}$ for a normal start and from 4.0 to $7.0 \mathrm{~m} . \mathrm{s}^{-2}$ for maximum start. With a passenger, the values could be one third lower (Burg \& Moser, 2014; Hugemann, 2007). Acceleration of a supersport motorcycle is described in a study by Gallego (2011), the maximum values reached an acceleration of up to $6.0 \mathrm{~m} . \mathrm{s}^{-2}$. In Sedlak \& Slepanek (2012), six motorcycles were measured, which had acceleration values in the range from 3.2 to $4.4 \mathrm{~m} . \mathrm{s}^{-2}$. These were mostly fast starts. The author had previously dealt with measuring the acceleration of vehicles at the first and second gears (Slepanek, 2010). Semela (2012) is also mentioning the acceleration of motorcycles. Another work (Friedel, 2013) deals with the lateral acceleration of the motorcycle, but there is also a reference to the brake deceleration and acceleration to the individual gears of a large set of motorcycles. The motorcycle acceleration measurement at the first and second gears is described in Walus et al. (2017), the acceleration was $1.7 \mathrm{~m} . \mathrm{s}^{-2}$ at the first gear and $1.1 \mathrm{~m} . \mathrm{s}^{-2}$ at the second gear. In Bokare \& Maurya (2016), a set of acceleration measurements of different vehicle types including motorcycles were achieved, reaching the maximum values of $2.0 \mathrm{~m} . \mathrm{s}^{-2}$ in case of motorcycles. Motorcycle acceleration value with the Acc Box system device is stated in Lofwall (2012). Measurement of motorcycle ride dynamics including acceleration is described in Kobosil (2016).

For the analysis of road accidents, a large number of specialized literature was gathered in the publication of Bradac et al. (1999), where the analysis of road accidents is very well described in detail. The issue of motorcycle dynamics is well evaluated in the studies of Kasanicky \& Kohut (2000), Hugemann (2007), Rabek (2009), Semela (2012) and Burg \& Moser (2014).

The aim of the measurement provided by this article was to determine the acceleration values of a motorcycle at normal starting, when the maximum speed was $40 \mathrm{~km} / \mathrm{h}, 50 \mathrm{~km} / \mathrm{h}$ and $60 \mathrm{~km} / \mathrm{h}$. The normal start was neither fast (accelerated acceleration), nor slow (very slow acceleration). It was the starting during which most motorcyclists accelerate from zero speed, for example, from a junction in normal road traffic. The maximum speed limit was selected for normal traffic in cities. A set of different measurements is performed in the article, which serves to supplement and refine the input data for the analysis of road accidents involving motorcycles. Measured data can be useful for quality processing of expert opinions. The resulting acceleration values can be used to solve traffic accidents not only in urban traffic. 


\section{Measurements:}

\section{Measuring equipment}

Measurements were made using the XL METR ${ }^{\mathrm{TM}}$ PRO GAMMA device. It is a universal meter with an alphanumeric display that is powered by integrated batteries.

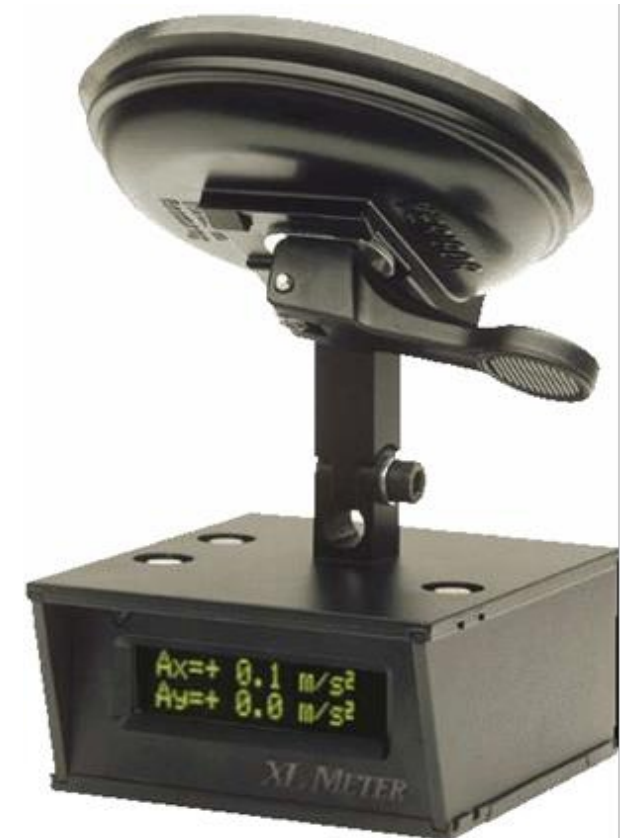

Picture No. 1 -XL METR ${ }^{\mathrm{TM}}$ PRO GAMMA measuring device

$\mathrm{XL}_{\text {METR }}{ }^{\mathrm{TM}}$ PRO GAMMA is used to measure longitudinal and transverse (depending on installation) acceleration or deceleration. The device is suitable for a comprehensive measurement of the driving dynamics of motorcycles and vehicles.

Table No. 1 - Technical parameters of the XL METR ${ }^{T M}$ PRO GAMMA device

\begin{tabular}{|l|l|}
\hline Maximum number of recorded measurements: & 8 \\
\hline Memory capacity: & $3 \times 80 \mathrm{~s}+5 \times 40 \mathrm{~s}$ \\
\hline Frequency of writing data: & $200 \mathrm{~Hz} \ldots 25 \mathrm{~Hz}$ \\
\hline Measuring range: & -20 to $20{\mathrm{~m} . \mathrm{s}^{-2}}^{-2}$ \\
\hline Sensitivity: & $0.002 \mathrm{~m} . \mathrm{s}^{-2}$ \\
\hline PC Interface: & $\mathrm{RS} 232, \mathrm{USB}$ \\
\hline Display: & $16 \times 2$ PLED or LCD illumination \\
\hline Dimensions (H x W x D): & $50 \times 97 \times 110 \mathrm{~mm}$ \\
\hline External power supply: & 6 to $18 \mathrm{~V}$ DC \\
\hline Battery: & $4 \times$ AA type \\
\hline
\end{tabular}

\section{Measured motorcycle}

Measured motorcycle, the Honda CBR $1000 \mathrm{~F}$, was fitted as standard with a 42-liter rear plastic case installed on it. 


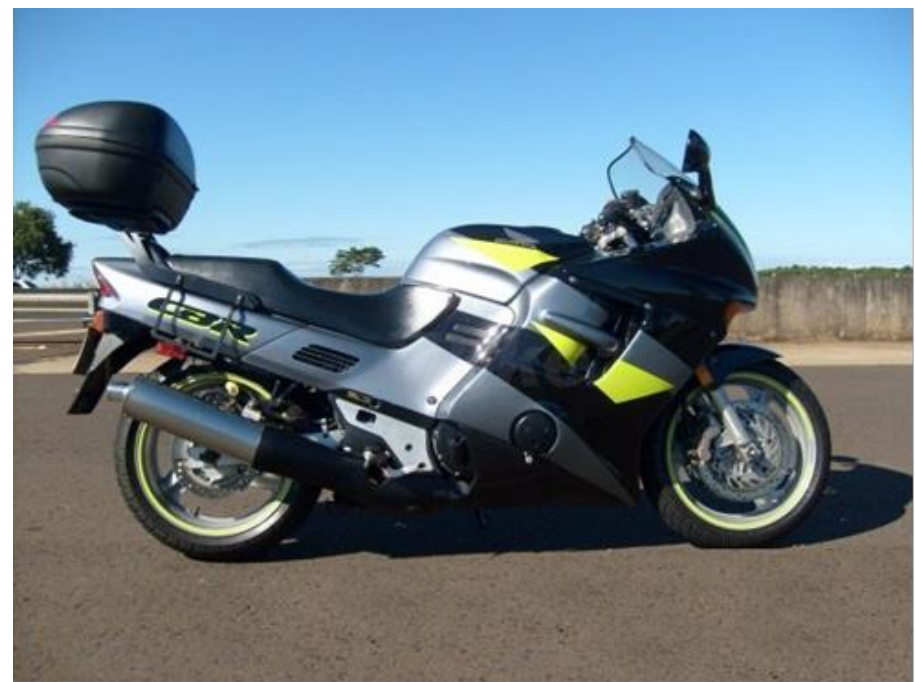

Picture No. 2 - Honda CBR 1000 F motorcycle

Basic parameters of the motorcycle:

- year of manufacture

1993

- engine capacity

$998 \mathrm{ccm}$

- engine power

$95 \mathrm{~kW}$ at 9,500 RPM

- weight

$235 \mathrm{~kg}$

- $\mathrm{km}$ state

$68,000 \mathrm{~km}$

\section{Installation of the XL METR ${ }^{T M}$ PRO GAMMA device on a motorcycle}

The measuring device was installed on a motorcycle's fuel tank by means of a vacuum suction device which is connected to a separate device by means of a hinge arm. An adhesive tape was used for a stronger joint.

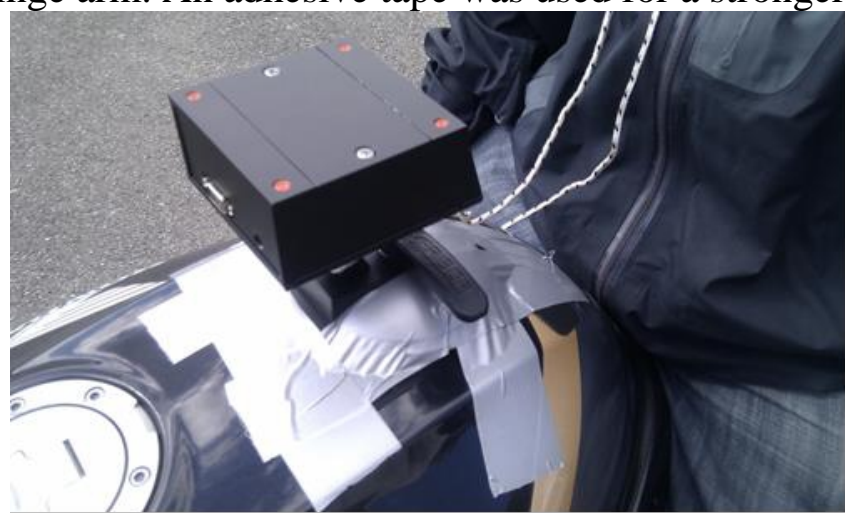

Picture No. 3 - Installation of the XL METR ${ }^{T M}$ PRO GAMMA device on the fuel tank of the Honda CBR $1000 \mathrm{~F}$ motorcycle 


\section{Place of the measurement}

The measurement of motorcycle's acceleration took place at a parking area in the village of Jedovnice near the Olšovec pond (Blansko district, Czech Republic). The car park was about $200 \mathrm{~m}$ long and about $40 \mathrm{~m}$ wide, with no longitudinal and lateral inclination. The surface of the car park was an asphalt surface without any significant unevenness.

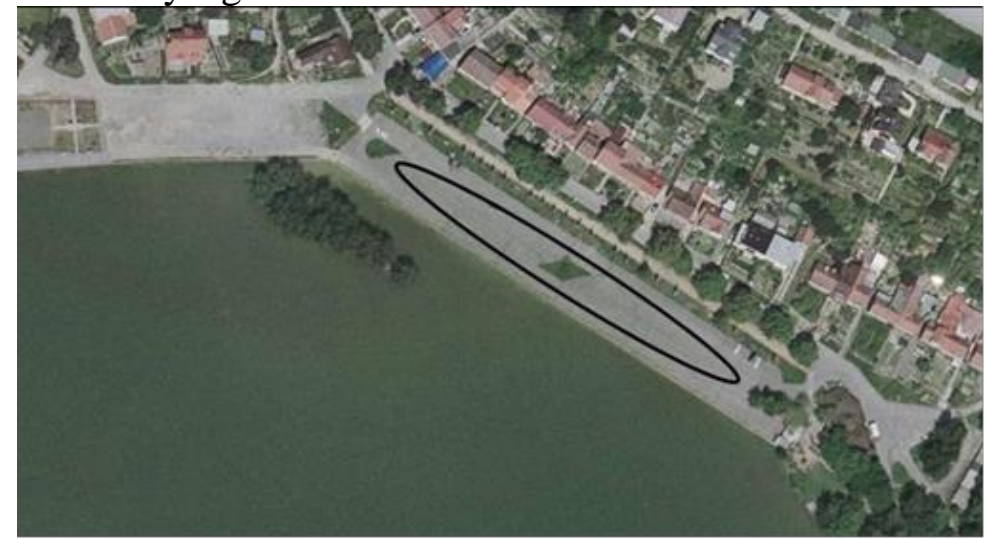

Picture No. 4-Place of measurement

\section{Climate measurement conditions}

At the time of the measurement, weather conditions were constant, clear, no wind, temperature at $19{ }^{\circ} \mathrm{C}$.

\section{Measurement procedure}

The motorcycle acceleration measurement was performed three times for each desired speed to achieve more accurate results. After acceleration, the speed of the motorcycle was stabilized at $40 \mathrm{~km} / \mathrm{h}, 50 \mathrm{~km} / \mathrm{h}$ and $60 \mathrm{~km} / \mathrm{h}$. The result of the measurements has been represented by a table containing a total of eight measurements (one record was not evaluated).

\section{Results of the measurement:}

The individual measurements were displayed using two graphs and one table. The first chart shows the overall measurement. Positive values indicate the acceleration of the motorcycle, values dropping to zero acceleration show the shift to higher gears, and negative acceleration values correspond with motorcycle braking. The time delay without acceleration (from the beginning of the measurement) means that the XL METR ${ }^{\mathrm{TM}}$ PRO GAMMA device was launched before the motorcycle started to accelerate. Between acceleration and braking, there is an area where the speed has stabilized to the desired value (the acceleration value varies around the zero value). The next chart shows a more detailed part of a graph illustrating the acceleration of the motorcycle (first, second and third gear), followed by 
stabilizing the speed to the desired value. The vertical axis of the chart shows the acceleration (deceleration) of the motorcycle $-\mathrm{a}\left[\mathrm{m} \cdot \mathrm{s}^{-2}\right]$, and the horizontal axis shows time - $t[\mathrm{~s}]$. The last information element is represented by tables where the average values of the individual measurements are recorded. Since there was a large number of measurements, display of which would be very large, only 3 measurements of the motorcycle acceleration followed by a stabilization of speed at $40 \mathrm{~km} / \mathrm{h}, 50 \mathrm{~km} / \mathrm{h}$ and $60 \mathrm{~km} / \mathrm{h}$ are stated.

\section{Acceleration of the motorcycle followed by constant speed of $40 \mathrm{~km} / \mathrm{h}$}

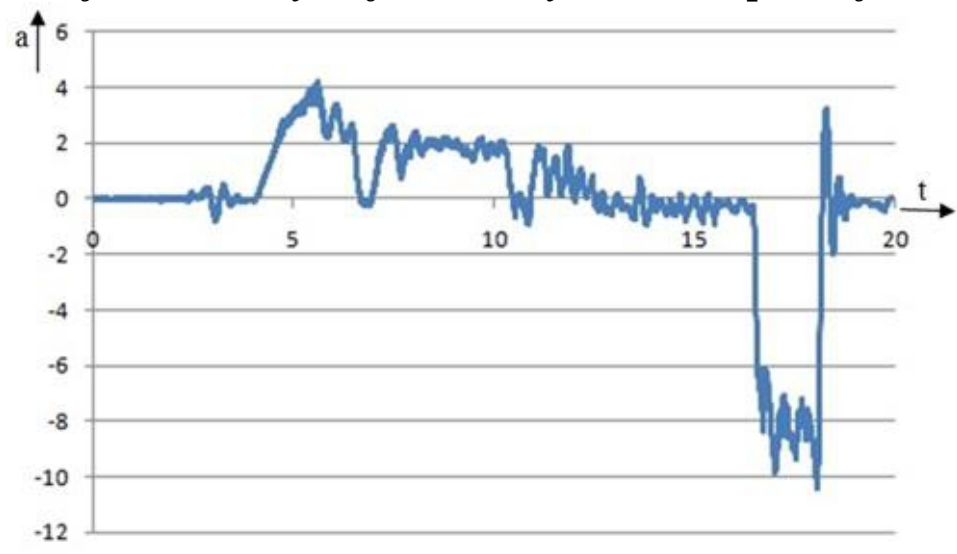

Graph No. 1 - Graph of all the measurements of the Honda motorcycle

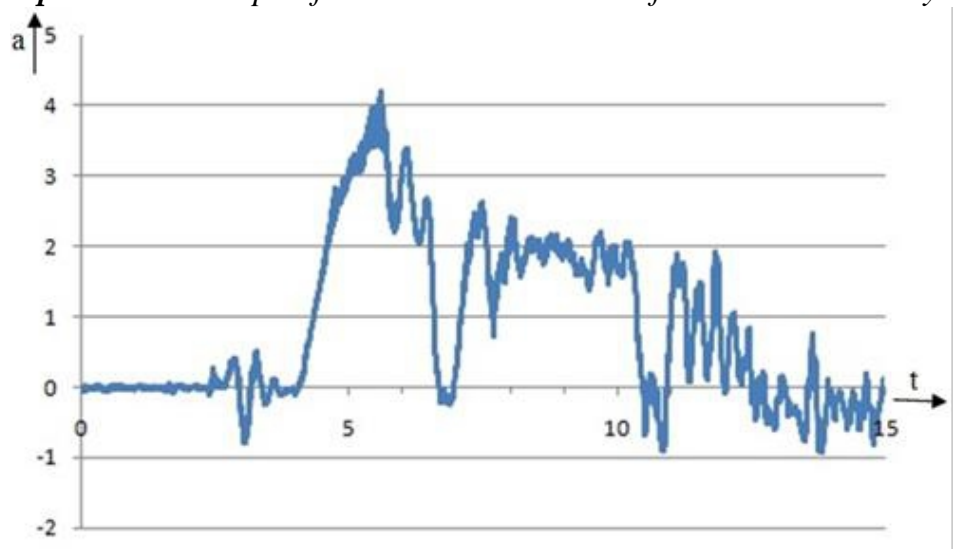

Graph No. 2 - Detail of a graph-normal acceleration followed by constant speed of 40 $\mathrm{km} / \mathrm{h}$

The acceleration of the motorcycle in the case of the first measurement reached the average values of $2.6 \mathrm{~m} \cdot \mathrm{s}^{-2}$ in the first gear, $1.9 \mathrm{~m} \cdot \mathrm{s}^{-2}$ in the second gear and $1.0 \mathrm{~m} . \mathrm{s}^{-2}$ in the third gear. The average total acceleration was $1.8 \mathrm{~m} . \mathrm{s}^{-}$ 2 . 
Table No. 2 - Chart of values of acceleration followed by constant speed of $40 \mathrm{~km} / \mathrm{h}$

\begin{tabular}{|c|c|c|c|}
\hline Motorcycle & Speed & $\begin{array}{c}\text { Measurement } \\
\text { no. }\end{array}$ & $\begin{array}{c}\text { XL METRTM PRO GAMMA - } \\
\text { acceleration a }\left[\mathrm{m}_{\mathrm{s}} \mathrm{s}^{-2}\right]\end{array}$ \\
\hline \multirow{2}{*}{$\begin{array}{c}\text { Honda CBR } \\
1000 \mathrm{~F}\end{array}$} & \multirow{3}{*}{$40 \mathrm{~km} / \mathrm{h}$} & 1 & 1.8 \\
\cline { 3 - 4 } & 2 & 2.0 \\
\cline { 3 - 4 } & & 2 & 2.1 \\
\hline
\end{tabular}

\section{Acceleration of the motorcycle followed by constant speed of $50 \mathrm{~km} / \mathrm{h}$}

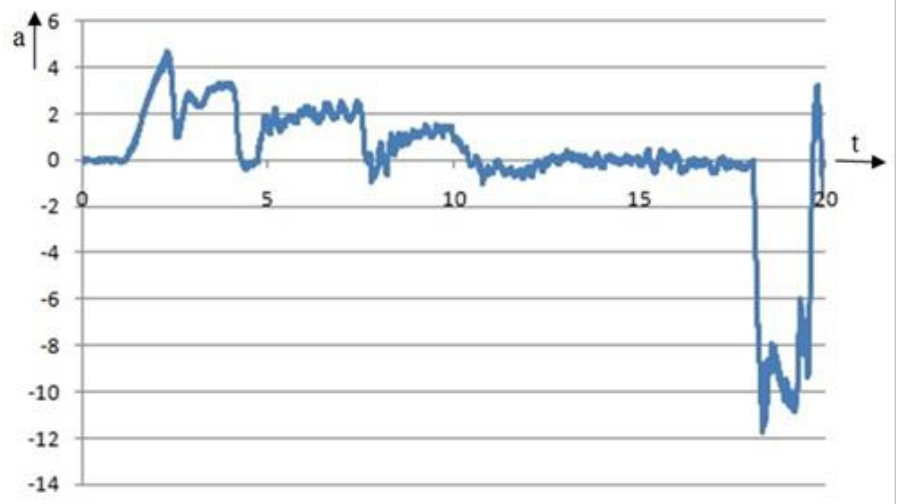

Graph No. 3 - Graph of all the measurements of the Honda motorcycle

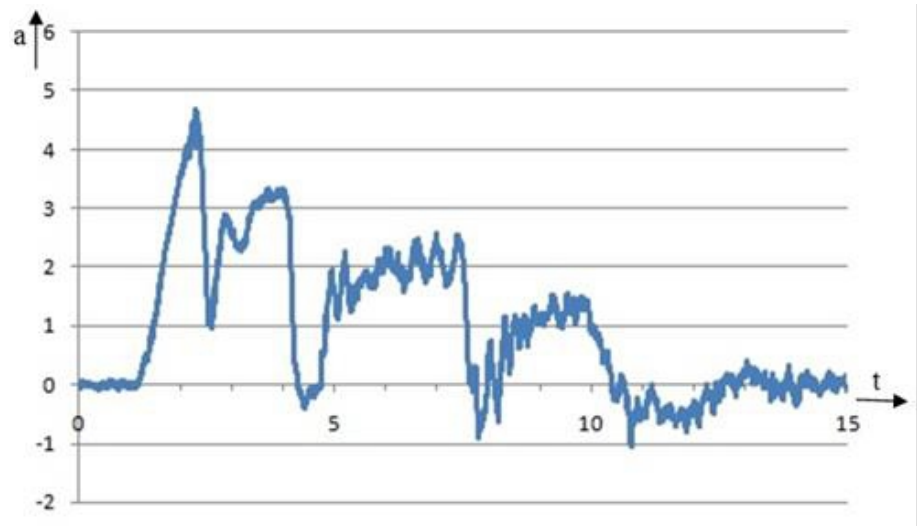

Graph No. 4 - Detail of a graph - normal acceleration followed by constant speed of 50 $\mathrm{km} / \mathrm{h}$

The acceleration of the motorcycle in the fourth measurement reached the average values of $2.8 \mathrm{~m} . \mathrm{s}^{-2}$ in the first gear, $1.9 \mathrm{~m} . \mathrm{s}^{-2}$ in the second gear and $0.9 \mathrm{~m} . \mathrm{s}^{-2}$ in the third gear. The average total acceleration was $1.9 \mathrm{~m} . \mathrm{s}^{-2}$.

Table No. 3 - Chart of values of acceleration followed by constant speed of $50 \mathrm{~km} / \mathrm{h}$

\begin{tabular}{|c|c|c|c|}
\hline Motorcycle & Speed & $\begin{array}{c}\text { Measurement } \\
\text { no. }\end{array}$ & $\begin{array}{c}\text { XL METR } \\
\text { acceleration } \mathrm{a}\left[\mathrm{m}_{\mathrm{s}} \mathrm{s}^{-2}\right]\end{array}$ \\
\hline \multirow{2}{*}{$\begin{array}{c}\text { Honda CBR } \\
1000 \mathrm{~F}\end{array}$} & \multirow{3}{*}{$50 \mathrm{~km} / \mathrm{h}$} & 4 & 1.9 \\
\cline { 3 - 4 } & & 5 & 2.2 \\
\hline
\end{tabular}




\section{Acceleration of the motorcycle followed by stabilization at $60 \mathrm{~km} / \mathrm{h}$}

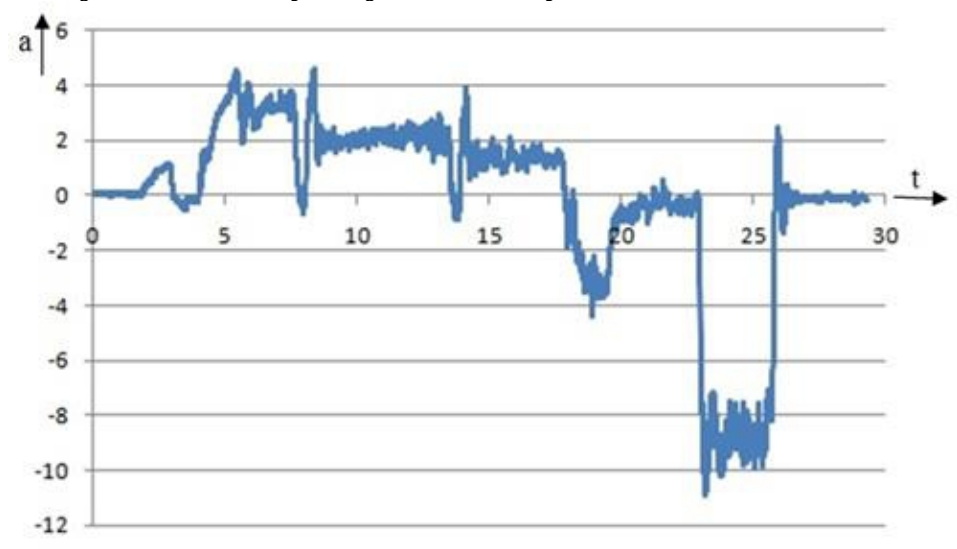

Graph No. 5 - Graph of all the measurements of the Honda motorcycle

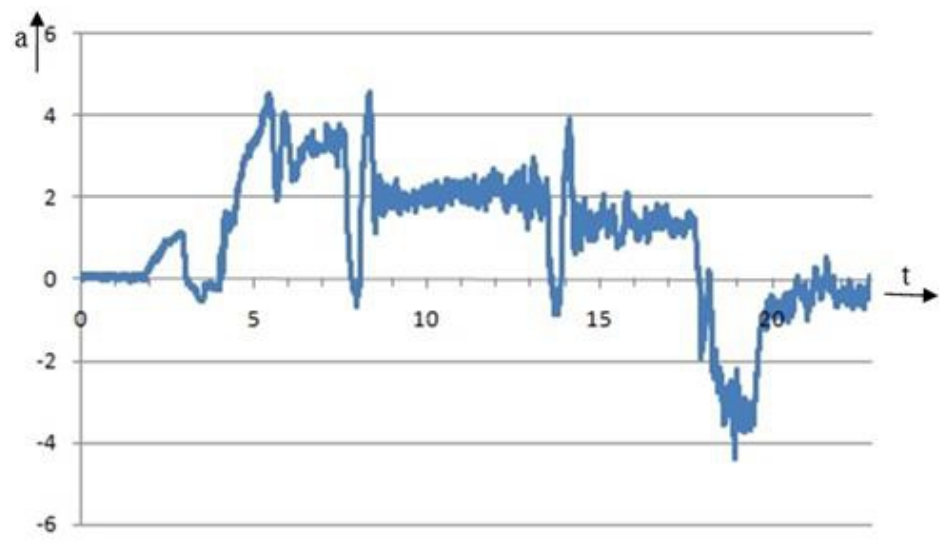

Graph No. 6 - Detail of a graph - normal acceleration followed by constant speed of 60 $\mathrm{km} / \mathrm{h}$

Table No. 4 - Chart of the values of acceleration followed by constant speed of $60 \mathrm{~km} / \mathrm{h}$

\begin{tabular}{|c|c|c|c|}
\hline Motorcycle & Speed & $\begin{array}{c}\text { Measurement } \\
\text { no. }\end{array}$ & $\begin{array}{c}\text { XL METR } \\
\text { acceleration } \mathrm{a}\left[\mathrm{m}_{\mathrm{s}} \mathrm{s}^{-2}\right]\end{array}$ \\
\hline \multirow{2}{*}{$\begin{array}{c}\text { Honda CBR } \\
1000 \mathrm{~F}\end{array}$} & \multirow{3}{*}{$60 \mathrm{~km} / \mathrm{h}$} & 7 & 2.1 \\
\cline { 3 - 4 } & & 8 & 2.2 \\
\cline { 3 - 4 } & & 9 & Data could not be downloaded \\
\hline
\end{tabular}

\section{Conclusion}

Currently, there are not enough technically acceptable parameters for motorcycle acceleration. That is why the author decided to measure the motorcycle acceleration using the XL METR ${ }^{\mathrm{TM}}$ PRO GAMMA device, which has a wide range of applications for measuring dynamic parameters of motorcycles. Acceleration in two axes can be measured with the device, which is sufficient to measure the acceleration or deceleration of motorcycles. 
Measured values using XL METR ${ }^{\mathrm{TM}}$ PRO GAMMA are very accurate and the output motorcycle acceleration values can be classified as technically acceptable. However, signal filtration was used to make the graphic results smoother. Due to rigid dampers, the effect of tilting forward and backward is not considered in the article. The situation would be different in the case of enduro motorcycles, where the tilting forward and backward has more pronounced acceleration.

For further research on dynamic parameters, however, I would recommend using more advanced three-axis accelerometers and three-axis gyroscopes. This method would allow to verify the results stated in this article. I would also recommend focusing on eliminating motorcycle's tilting forward and backward and tilting side to side.

The aim of this article was to measure the acceleration of the Honda CBR $1000 \mathrm{~F}$ motorcycle, followed by a speed of $40 \mathrm{~km} / \mathrm{h}, 50 \mathrm{~km} / \mathrm{h}$ and $60 \mathrm{~km} / \mathrm{h}$. For more accurate results, each measurement was repeated three times (except for the last one when a PC communication error occurred at $60 \mathrm{~km} / \mathrm{h}$ ). The results of the measurements were the average acceleration graphs, one for each constant speed. The complete measurement data are shown in the tables. Motorcycle acceleration values followed by a speed stabilization at $40 \mathrm{~km} / \mathrm{h}$ ranged from 1.8 to $2.1 \mathrm{~m} . \mathrm{s}^{-2}$. Motorcycle acceleration values followed by a speed stabilization at $50 \mathrm{~km} / \mathrm{h}$ ranged from 1.9 to $2.2 \mathrm{~m} . \mathrm{s}^{-}$ ${ }^{2}$. Motorcycle acceleration values followed by a speed stabilization at $60 \mathrm{~km} / \mathrm{h}$ ranged from 2.1 to $2.2 \mathrm{~m} . \mathrm{s}^{-2}$.

The detected acceleration values in this measurement can be considered as mean values, given the character of acceleration. The acceleration of the motorcycle was normal - neither fast, nor slow. Another topic for a measurement could be a set of both fast and slow motorbike accelerations. It would also be appropriate to conduct measurements with more motorcyclists of different age categories, different sexes, with different riding experience, etc. Further research could be focused on measuring acceleration of current motorcycles of different styles and cubatures, at all gears. It would also be very interesting to measure acceleration of differently loaded motorcycles (a motorcycle with a motorcyclist, a motorcycle with a motorcyclist and a co-driver, or a motorcycle with a load).

The acquired data could be useful to experts for solving traffic accidents in which a motorcycle was present.

\section{References:}

1. Bradac, A et all. (1999). Soudni inzenyrstvi. Akademicke nakladatelstvi CERM, Brno.

2. Kasanicky, G., Kohut, P. (2000). Analyza nehod jednostopovych vozidel. Zilinska universita v Ziline, Zilina. 
3. Burg, H., Moser, A. (2014). Handbook of accident rekonstruction.

4. Hugemann, W. (2007). Unfall rekonstruktion.

5. Semela, M. (2012). Analyza silnicnich nehod II. USI. Brno.

6. Rabek, V. (2009). Vybrané postupy analýzy dopravních nehod.

7. Fridel, D. (2013). Analyza doby pricneho premisteni motocyklu. USI. Brno.

8. Sedlak, R., Slepanek, P. (2012). Zrychleni/zpomaleni motocyklu a automobilu. VUT v Brne, USI. Brno.

9. Slepanek, P. (2010). Mereni zrychleni vozidel na prvni a druhy rychlostni stupen. Soudni inzenyrstvi. Akademicke nakladatelstvi CERM, Brno.

10. Gallego, M. (2011). Analysis of dynamic handling of one motorcycle using simulations tools. AGH. Krakow.

11. Walus, $\mathrm{K}$ et all. (2017). The impact of the modernization of the injection-ignition system on the parameters of motion of the motorcycle. Poznan.

12. Bokare, P., Maurya, A. (2016). Acceleration-Deceleration behaviour of various vehicle types. WCTR. Shanghai.

13. Lofwall, T. (2012). Measuring Acceleration in Vehicles using the Acc Box system. Uppsala.

14. Kobosil, M. (2016). Mereni dynamiky jizdy systemu ridic - motocykl. Praha. 